\title{
DEVELOPMENT OF AN INDICATOR BASED TOOL FOR THE ASSESSMENT OF MEDICINES SELECTION PRACTICES IN VARIOUS PUBLIC SECTOR HOSPITALS
}

\author{
MIR JAVID IQBAL ${ }^{1}$, MOHAMMAD ISHAQ GEER ${ }^{1 *}$, PARVEZ AHAMD DAR ${ }^{2}$ \\ ${ }^{1}$ Department of Pharmaceutical Sciences, University of Kashmir, Srinagar 190006, J and K, India,²Department of Paediatrics, Govt. Medical \\ College, Srinagar 190001, J and K, India \\ Email: ishaqgeer@gmail.com
}

Received: 06 Aug 2016 Revised and Accepted: 09 Sep 2016

\begin{abstract}
Objective: To develop and validate an indicator based assessment tool for carrying out an in-depth assessment of drug selection practices prevalent at various public health facilities.

Methods: The study was designed across the different levels of healthcare settings. One super specialty children's tertiary care hospital (CH), one government medical college hospital (MCH), one district hospital (DH), one sub-district hospital (SDH) and one primary health center (PHC) was selected for the study. A set of 29 qualitative and 7 quantitative indicators was developed and validated to evaluate and assess drug selection
\end{abstract} practices in these public healthcare facilities.

Results: All the surveyed healthcare facilities managed and stored essential medicines except solid oral dosage forms, contraceptives, antiretrovirals and anti-tubercular drugs. The selection process for medicines was not carried out at SDH and PHC level. National List of Essential Medicines (NLEM), manufacturer's information, and expert faculty opinion were used as basic tools for carrying out a selection of drugs. None of the facilities were found to have Drugs and Therapeutics Committee (DTC) in place or its own Hospital Formulary (HF). Insufficient and irregular disbursement of funds was found to be the main constraint in selecting drugs for procurement. None of the facilities had any policy and procedural manual or standard operating procedures for governing their drug selection and quantification processes. Quantitative assessments showed that disbursement of the budget was fragmented. On the basis of NLEM children's hospital was found to have highest medicines percentage availability of eighty percent (80\%) with the lowest at SDH and PHC of twenty percent each (20\%). Facility wise percentage adherence to various indicators for policies and procedures was found to be $50 \%$ in $\mathrm{MCH}, \mathrm{CH}$, and $\mathrm{DH}$ respectively and $66.6 \%$ adherence for NLEM indicator was recorded in $\mathrm{MCH}, \mathrm{CH}$ and $\mathrm{DH}$ respectively.

Conclusion: Drug selection process for public health facilities is a highly technical and professional activity that can only be achieved efficiently by having a well-defined document containing Standard Operating Procedures (SOPs) and comprehensive policy framework for drug selection, quantification, procurement, storage, distribution, and use besides having suitably qualified, adequately trained, sufficiently skilled manpower both at managerial and ground level.

Keywords: Indicator, Assessment, Selection, Tertiary care, National List of Essential Medicines

(C) 2016 The Authors. Published by Innovare Academic Sciences Pvt Ltd. This is an open access article under the CC BY license (http://creativecommons.org/licenses/by/4. 0/) DOI: http://dx.doi.org/10.22159/ijpps.2016v8i11.14536

\section{INTRODUCTION}

Medicines are among the most valuable forms of healthcare and are instrumental in treating various diseases more effectively [1]. An efficient and robust medicines management ensure rational selection, quantification, procurement, storage, distribution, use and thereby availability of the right drugs in the right quantities, at reasonable prices, and at recognized standards of quality. Selecting essential medicines start with defining and compiling a list of common diseases for each level of healthcare. The rationale for selecting a limited number of essential medicines is that it leads to better supply, more rational use, and lower costs [2].

Rapid assessments may be indicated when the existing management information system is unable to track the performance of the pharmaceutical system in place, or when drug problems needing urgent attention are evident. A structured and rigorous evaluation of supply chain interventions is of immense importance and greatly benefits the supply chain [3]. The World Health Organization (WHO) has recognized the need for the development of formal indicators that would facilitate comparative analysis of pharmaceutical systems and their efficiencies [4]. A way forward in this direction our study was the first of its kind in India, which aimed at developing an indicator based assessment tool that could be used to assess and evaluate the existing medicines management practices prevalent in our public health facilities. This would help hospitals to carry out an in-depth assessment of their existing practices, which would further help them to make the best and efficient use of their available resources for making quality medicines available and affordable to their patients throughout the year without any breakups.

\section{MATERIALS AND METHODS}

This study was carried out in five government, public health facilities of one district across all the three levels of care. Five public health facilities comprised of one Medical College Hospital (MCH), one tertiary care Children's Hospital $(\mathrm{CH})$, one tertiary care District Hospital (DH), one secondary care Sub-District Hospital (SDH) and one Primary Healthcare Centre (PHC). Thus three tertiary care, one secondary care and one primary care hospital in government sector were selected for the present study.

The criteria for selection of these sites was based on, the intensity and significance of the health service activities carried out by them and the presence of a comprehensive health system structure is comprising of all the three levels. $\mathrm{CH}, \mathrm{MC}, \mathrm{DH}$ and SDH were chosen were the only public health facilities available in the study district. A set of 29 qualitative and 07 quantitative indicators were developed, validated and used to assess and evaluate various existing practices governing the selection of drugs in these public health facilities.

\section{RESULTS}

Table 1 shows that all the surveyed healthcare facilities managed and stored essential medicines, including Medical/surgical supplies, however, solid oral dosage forms contraceptives, antiretrovirals, and anti-tubercular drugs were not managed and kept available at these public healthcare facilities. 
National List of Essential Medicines (NLEM), manufacturer's information, and expert faculty opinion were used as basic tools for carrying out a selection of drugs at three of the study facilities namely $\mathrm{MCH}, \mathrm{DH}$ and $\mathrm{CH}$ shown in table 2.

None of the facilities were found to have DTC in place. The selection of drugs at these facilities was carried out on the basis of the NLEM and past drug consumption patterns along with senior medical faculty member opinions. None of the facilities were found to have a copy of the NLEM available in their facility. Moreover, none of the facilities were found to have their own hospital formulary or hospital specific essential medicines list as shown in table 3 .

Selection, quantification, procurement and distribution of drugs at PHC and SDH level facilities was carried out by the directorate of health services, Kashmir division annually on the basis of their indented requisitions, annual work done reports, available funds and some other considerations.

Table 3 shows that medicines selection committees' were found to be responsible for the selection of medicines at $\mathrm{CH}, \mathrm{MC}$ and $\mathrm{DH}$, however, none of the committees were found to have a pharmacist as one of its members. Insufficient and irregular disbursement of funds was found to be the main constraint in selecting drugs for procurement. None of the facilities had any policy and procedural manual or SOPs for carrying out their selection and quantification of drugs.

Quantitative assessments showed that disbursement of the budget was fragmented and funds from the annual budget were released on quarterly basis, i.e., 25 percent in one go. $\mathrm{CH}$ was found to have highest medicines percentage availability of 80 percent with the lowest of 20 percent at SDH and PHC respectively as shown in table 3.

Table 1: Different categories of medicines managed at surveyed public health facilities

\begin{tabular}{|c|c|c|c|c|c|c|}
\hline \multirow[t]{2}{*}{ S. No. } & \multirow[t]{2}{*}{ Category of products } & \multicolumn{5}{|c|}{ Health facility } \\
\hline & & MCH & $\mathbf{C H}$ & DH & SDH & PHC \\
\hline 1. & Solid oral dosage forms. & 2 & 2 & 2 & 1 & 1 \\
\hline 2. & Contraceptives & 2 & 2 & 2 & 1 & 1 \\
\hline 3. & Anti-retrovirals & 2 & 2 & 2 & 2 & 2 \\
\hline 4. & Medical/Surgical supplies & 1 & 1 & 1 & 1 & 2 \\
\hline 5. & Pediatric formulations & 1 & 1 & 1 & 1 & 1 \\
\hline 6. & Anti-tubercular medicines & 2 & 2 & 2 & 2 & 2 \\
\hline 7. & Vaccines & 2 & 2 & 1 & 1 & 1 \\
\hline
\end{tabular}

1=Yes 2=No, MCH=Medical College Hospital, $\mathrm{CH}=$ =Children's Hospital, DH=District Hospital, SDH= Sub District Hospital, PHC= Primary Health Centre

Table 2: Various tools and sources used for selection of medicines at surveyed public health facilities

\begin{tabular}{|c|c|c|c|c|c|c|}
\hline \multirow[t]{2}{*}{ S. No. } & \multirow[t]{2}{*}{ Tools/sources } & \multicolumn{5}{|c|}{ Health facility } \\
\hline & & MCH & CH & DH & SDH & PHC \\
\hline 1. & Drugs and Therapeutics Committee (DTC) & 2 & 2 & 2 & NA & NA \\
\hline 2. & National List of Essential Medicines(NLEM) & 1 & 1 & 1 & NA & NA \\
\hline 3. & National Formulary (NF) & 2 & 2 & 2 & NA & NA \\
\hline 4. & Hospital Formulary (HF) & 2 & 2 & 2 & NA & NA \\
\hline 5. & Standard Treatment Guidelines (STG) & 2 & 2 & 2 & NA & NA \\
\hline 6. & Manufacturer's Information & 1 & 2 & 1 & NA & NA \\
\hline 7. & Expert/Faculty Opinion & 1 & 1 & 1 & NA & NA \\
\hline 8. & Drug consumption data & 1 & 1 & 1 & 1 & 1 \\
\hline 9. & Defined Daily Dose & 2 & 2 & 2 & 2 & 2 \\
\hline
\end{tabular}

1=Yes 2=No NA=Not Applicable, MCH=Medical College Hospital, $\mathrm{CH}=$ Children's Hospital, DH=District Hospital, SDH= Sub District Hospital, PHC= Primary Health Centre

Table 3: Qualitative indicator based assessment of various drug selection practices at surveyed public health facilities

\begin{tabular}{|c|c|c|c|c|c|c|c|}
\hline \multirow{2}{*}{$\begin{array}{l}\text { S. } \\
\text { No. }\end{array}$} & \multirow[t]{2}{*}{ Qualitative indicator } & \multicolumn{6}{|c|}{ Response } \\
\hline & & MCH & CH & DH & SDH & PHC & $\begin{array}{l}\text { Percent } \\
\text { adherence }\end{array}$ \\
\hline \multicolumn{8}{|c|}{ Policies and procedures } \\
\hline 1. & There is an official medicines committee for selection of drugs & 1 & 1 & 1 & NA & NA & 100 \\
\hline 2. & All stakeholders are a part of the selection committee & 2 & 2 & 2 & NA & NA & $\mathbf{0}$ \\
\hline 3. & The selection of drugs is done according to the needs of patients. & 1 & 1 & 1 & NA & NA & 100 \\
\hline 4. & Selection criteria is based on proven efficacy, safety, quality, and cost. & 1 & 1 & 1 & NA & NA & 100 \\
\hline 5. & Sufficient and timely disbursement of funds (budget) is ensured & 2 & 2 & 2 & NA & NA & $\mathbf{0}$ \\
\hline 6. & Availability of policies and procedures manual (SOPs) for selection of drugs. & 2 & 2 & 2 & NA & NA & $\mathbf{0}$ \\
\hline Per & tage adherence & 50 & 50 & 50 & - & - & 50 \\
\hline \multicolumn{8}{|c|}{ Drugs and therapeutics committee } \\
\hline 7. & DTC is in place & 2 & 2 & 2 & 2 & NA & $\mathbf{0}$ \\
\hline 8. & DTC document indicates its terms of reference & 2 & 2 & 2 & 2 & NA & $\mathbf{0}$ \\
\hline 9. & DTC fig. in the organizational chart of the hospital. & 2 & 2 & 2 & 2 & NA & $\mathbf{0}$ \\
\hline 10. & DTC is involved in selection of drugs. & 2 & 2 & 2 & 2 & NA & $\mathbf{0}$ \\
\hline 11. & DTC has established criteria and authority concerning the drug selection. & 2 & 2 & 2 & 2 & NA & $\mathbf{0}$ \\
\hline 12. & DTC is active in the development and implementation of STGs/HF/EDL & 2 & 2 & 2 & 2 & NA & $\mathbf{0}$ \\
\hline 13. & The hospital has developed/adopted its own STGs. & 2 & 2 & 2 & 2 & NA & $\mathbf{0}$ \\
\hline 14. & Drug utilization studies have been performed to assess adherence to STGs & 2 & 2 & 2 & 2 & NA & $\mathbf{0}$ \\
\hline 15. & DTC organized educational activities about medicines in the past. & 2 & 2 & 2 & 2 & NA & $\mathbf{0}$ \\
\hline 16. & DTC is involved in the drug budget al. location or disbursement. & 2 & 2 & 2 & 2 & NA & 0 \\
\hline
\end{tabular}




\begin{tabular}{|c|c|c|c|c|c|c|c|}
\hline 17. & DTC clearance is needed prior to drug budget approval. & 2 & 2 & 2 & 2 & NA & $\mathbf{0}$ \\
\hline 18. & $\begin{array}{l}\text { Policy for controlling access of medical representatives and promotional literature to } \\
\text { hospital staff is in place. }\end{array}$ & 2 & 2 & 2 & 2 & NA & $\mathbf{0}$ \\
\hline \multirow{2}{*}{\multicolumn{8}{|c|}{$\begin{array}{l}\text { Percentage adherence } \\
\text { Essential Medicines List (EML) }\end{array}$}} \\
\hline & & & & & & & \\
\hline 19. & There is the availability of an EML in the facility & 2 & 2 & 2 & NA & NA & 100 \\
\hline 20. & Selection of drugs is based on EML & 1 & 1 & 1 & NA & NA & 100 \\
\hline 21. & EML has been updated and distributed in past five years & 2 & 2 & 2 & NA & NA & $\mathbf{0}$ \\
\hline 22. & Drugs are categorized into basic, supplementary and specialized lists. & 1 & 1 & 1 & NA & NA & 100 \\
\hline 23. & $\begin{array}{l}\text { While selecting formulation types, are stable forms chosen, to achieve a low-cost, high } \\
\text { impact }\end{array}$ & 1 & 1 & 1 & NA & NA & 100 \\
\hline 24. & $\begin{array}{l}\text { Expensive combination drugs are avoided to reduce the actual cost of drugs to the } \\
\text { hospital }\end{array}$ & 1 & 1 & 1 & NA & NA & 100 \\
\hline Perc & tage adherence & 66.6 & 66.6 & 66.6 & - & - & 83.32 \\
\hline \multicolumn{8}{|c|}{ Hospital formulary } \\
\hline 25. & There is the availability of a hospital formulary at the health facility. & 2 & 2 & 2 & 2 & 2 & $\mathbf{0}$ \\
\hline 26. & $\begin{array}{l}\text { There is compliance with hospital formulary with selection, procurement and use of } \\
\text { medicines. }\end{array}$ & 2 & 2 & 2 & 2 & 2 & $\mathbf{0}$ \\
\hline 27. & $\begin{array}{l}\text { There are well-documented criteria for addition to and deletion from the list and } \\
\text { requests for the use of non-formulary medicines. }\end{array}$ & 2 & 2 & 2 & 2 & 2 & $\mathbf{0}$ \\
\hline 28. & Annual systematic reviews of all therapeutic drug classes is conducted. & 2 & 2 & 2 & 2 & 2 & $\mathbf{0}$ \\
\hline & Duplications, both therapeutic and pharmaceutical (dosage forms) are avoided. & 2 & 2 & 2 & 2 & 2 & $\mathbf{0}$ \\
\hline \multicolumn{2}{|r|}{ Percentage adherence } & $\mathbf{0}$ & $\mathbf{0}$ & $\mathbf{0}$ & $\mathbf{0}$ & 0 & 0 \\
\hline
\end{tabular}

1=Yes, $2=$ No, NA=Not Applicable, SOP=Standard Operating Procedure, STG= Standard Treatment Guideline, HF = Hospital Formulary, EML=Essential Medicines List, $\mathrm{MCH}=$ Medical College Hospital, $\mathrm{CH}=$ Children's Hospital, DH= District Hospital, SDH= Sub District Hospital, PHC= Primary Health Centre

Table 4: Quantitative indicator based assessment of various drug selection practices at surveyed public health facilities

\begin{tabular}{|c|c|c|c|c|c|c|c|}
\hline \multirow[t]{2}{*}{ S. No. } & \multirow[t]{2}{*}{ Quantitative indicators } & \multicolumn{6}{|c|}{ Response } \\
\hline & & MCH & $\mathbf{C H}$ & DH & SDH & PHC & Percent \\
\hline 1. & Frequency of release of allocated budgetary funds & Q & Q & Q & NA & NA & Adherence \\
\hline 2. & Percentage of budget al. location that is actually released in one installment & 25 & 25 & 25 & - & - & 25 \\
\hline 3. & Percentage patients who pay a charge for their drugs they receive in hospital & 5 & 10 & 10 & 0 & 0 & 5 \\
\hline 4. & Percentage of prescribed drugs available in the hospital & 30 & 80 & 30 & 20 & 20 & 36 \\
\hline 5. & Percentage availability of EML drugs in the hospital & 32 & 56.1 & 8.6 & 20.1 & 34.8 & 30.5 \\
\hline 6. & Number of medicines present in hospital formulary. & 0 & 0 & 0 & 0 & 0 & $\mathbf{0}$ \\
\hline 7. & Percentage of prescribed medicines present in hospital formulary. & 0 & 0 & 0 & 0 & 0 & $\mathbf{0}$ \\
\hline
\end{tabular}

$\mathrm{Q}=$ Quarterly NA=Not Applicable, MCH=Medical College Hospital, $\mathrm{CH}=$ Children's Hospital, DH= District Hospital, SDH= Sub District Hospital, PHC= Primary Health Centre, EML=Essential Medicines List

\section{DISCUSSION}

Pharmaceutical supply systems in many developing countries, including India, have severe problems, including ineffective procedures in the selection, poor quality control, and economically inefficient procurement [5]. Only drugs for which sound and adequate evidence of efficacy and safety in a variety of settings is available should be selected for procurement. Relative cost-effectiveness is a major consideration in the choice of drugs [6]. The findings of this study identified that only a limited number of drugs were managed at public health facilities, which were mostly injectable. Solid orals, contraceptives, antiretrovirals and anti-tubercular drugs were not part of a managed drug class within these healthcare facilities. Limited, fragmented and irregular disbursement of budgetary funds to the public health facilities was found to be the single most important constraint in ensuring the availability of these drugs. Since our public health facilities are entirely dependent upon government funds, such insufficiencies are bound to happen, therefore public health facilities must learn to develop their own resources and infrastructure so that some of the funds can be generated at the facility level itself. At government level, budgetary funds must be pooled under one head, and disbursement of funds should be regular so that drugs are selected and procured on time without any break-ups. Apart from budgetary limitations, low incidence and prevalence of Human Immune Virus (HIV) disease were also found to be a reason for not managing antiretroviral drugs at these facilities.

Rational selection of drugs for public health facilities is crucial, as drugs are the single most vital component of health care. Drug costs make up a majority of health-system pharmacy budgets, and budgeting for these expenses is an important function, but long-term programmatic and policy planning is essential for successful and effective management. It is now well-known, accepted and documented fact that out-of-pocket (OOP) payment for health care has pushed many people into poverty. The burden of purchasing medicines is very high in India; accounting for the second largest bulk of expenditure after food. OOP medical costs alone may push $2.2 \%$ of the population below poverty line in one year [7]. A study found that there were noticeable variations in the prices of different brands for the same class of drugs available in Indian market. Huge cost variation was found throughout for the majority of the formulations. Thus, the price control mechanism has an important role and has a positive impact on healthcare delivery system [8]. The findings of another study on consumption of healthcare resources and the associated economic costs in a sample of patients with diabetes type 2 mellitus showed considerable expenditure on healthcare costs [9].

In many developing countries, logistic systems for public health facilities have been managing essential drugs, contraceptives, and vaccines, however these systems have been found inefficient and in many cases incapable of providing adequate supplies on a timely basis [10]. Since the selection of drugs is basic and extremely important professional function, therefore pharmacist plays a central and pivotal role in this process, but somehow pharmacist role in selection and quantification of drugs was found to be limited in surveyed public health facilities. Our findings revealed that apart from NLEM, expert faculty opinion, most commonly from heads of various clinical departments was used in carrying out a selection of drugs. None of the facilities were found to have DTC in place. Even though the selection of drugs was found to be on the basis of the National List of Essential Medicines, however, none of the facilities were found to have a list of the NLEM in their facility. The selection 
of drugs based on opinions can lead to bias and the constitution of DTC in this regard is very important step. For the selection of drugs, DTC should be constituted at these health facilities with the allround participation of all stakeholders. Apart from ensuring rational drug selection DTC also helps in ensuring good procurement, distribution practices at health facilities.

A hospital based study carried out on improving the use of medicines in the Musanze district of Rwanda found that there were the frequent unavailability and stock-outs of essential drugs. As a remedial measure, DTC was constituted and pharmacists were involved in implementing DTC activities. Follow-up evaluation and assessment showed that the constitution of DTC resulted in the selection of more cost-effective essential drugs. There was a decrease in stock outs and better service to patients. The availability of essential medicines increased from $70.2 \%$ in October 2009 to $95.6 \%$ in April 2010 [11]. Another study carried out to check the availability of EDL and adherence to it for the selection of drugs found only $61 \%$ of the health facilities with a selection policy restricted to the EDL, while $39 \%$ of the facilities used the list as well as other drugs not included. Furthermore, it was found that availability of EDL at district pharmacies was low, as only $64 \%$ of the sites surveyed reported having the document. The lack of knowledge of the EDL and the existing gaps of the health system creates an environment where the use of only quality essential drugs cannot be guaranteed [12]. In another study carried out in Raichur India, it was revealed that the surveyed health facilities had no essential drugs list [13].

The results of the present study also revealed that none of the surveyed health facilities had their own hospital formulary, DTC, STGs, or hospital specific essential medicines list. $\mathrm{CH}$ was found to have highest medicines percentage availability of $80 \%$, whereas SDH and PHC recorded the lowest availability of $20 \%$ each. A well-formulated and locally customized EDL is imperative to make optimal use of the limited financial resources [14]. A study carried out in Srilanka showed an overall mean percent availability of 52 percent (Tertiary Hospital-62 percent; District Hospital-54 percent; PU-49 percent; CD-45 percent) [15]. A study carried out on the availability of essential drugs concluded that lack of adherence to the EDL, limited budgetary allocations, irregular and scattered disbursement of funds for medicines and poor medicines management infrastructure were mainly responsible for the poor public sector availability of essential drugs [16].

\section{CONCLUSION}

The results of this study call for a change and improvement in the present drug selection practices being followed in our public healthcare facilities. This can be done by adopting relevant national and international guidelines on medicine selection practices. However, there is a dire need to devise medicine management policy framework, which can be used as a guide for efficient management of medicine supplies in terms of their selection, quantification, procurement, distribution and safe use. Evaluation of the supply chain should be carried out regularly to monitor the performance. Moreover, facilityspecific policies and procedures with SOPs should be developed and adhered to for better compliance with well-established standards.

\section{ACKNOWLEDGEMENT}

We are thankful to the Medical superintendents, doctors, pharmacists, and other staff of health facilities as well as owners of private retail outlets visited during the study for their support and cooperation. We are also thankful to all concerned officials of the Department of Health and Medical Education of JandK state for their statutory approvals for conducting this study.

\section{ABBREVIATION}

CH: children's hospital, MCH: Medical College Hospital, DH district hospital, SDH: Sub District Hospital, PHC: Primary Health Centre, ARV: Anti-Retro Virals, NLEM: Anti-National List of Essential Medicines, EDL: Essential Drug List, DTC: Drugs and Therapeutics Committee, OOP: Out-Of-Pocket, SOP: Standard Operating Procedure.

\section{CONFLICT OD INTERESTS}

The authors declared no conflicts of interests.

\section{REFERENCES}

1. Grootendorst P, Pierard E, Shim M. Life expectancy gains from pharmaceutical drugs. A critical appraisal of the literature. Expert Rev Pharm Outcomes Res 2009;9:353-64.

2. Management Sciences for Health. International drug price indicator guide. Cambridge: Management Sciences for Health; 2012. Available from: http://erc.msh.org/dmpguide/ index.cfm?search_cat=yesanddisplay=yesandmodule $=\mathrm{dmp}$.

[Last accessed on 20 May 2016].

3. Chokshi M, Farooqui H, Selvaraj S, Kumar P. A cross-sectional survey of the models in Bihar and Tamil Nadu, India for pooled procurement of medicines. WHO; 2015.

4. Massele AY, Oforiadjei D, Laing RO. A study of prescribing patterns with special reference to drug use indicators in Dar es Salaam Region, Tanzania. Top Doc 1993;23:104-7.

5. Holloway K, Green T. Drugs, and therapeutics committees: a practical guide. World Health Organization department of essential drugs and medicines policy WHO/QSM; 2003. Available from: http://apps.who.int/medicinedocs/ pdf/ s4882e/s4882e.pdf. Last accessed on 26 Apr 2016].

6. WHO. World Health Organization. Procurement of vaccines for public-sector programs: a reference manual. Geneva: WHO; 1999. Available from: http://apps.who.int/medicinedocs/documents/ s17716en/s17716en.pdf [Last accessed on 10 Jun 2016].

7. World Bank. Procurement of pharmaceuticals and vaccines. Washington, DC: World Bank; 2001. Available from: https://openknowledge.worldbank.org/bitstream/handle/mul ti0page.pdf. [Last accessed on 26 Dec 2015].

8. Nerlekar S, Rashmi A, Karia S, Desousa A. Comparing prices of commonly used gastric acid suppressants available in india. Asian J Pharm Clin Res 2016;6:378-80.

9. Andayani T, Ibrahim M, Asdie A. Assessing the impact of complications on the direct medical costs of type 2 diabetes mellitus outpatients. Int J Curr Pharm Res 2010;2:32-5.

10. Bates J, Chandani Y, Crowley K, Durgavich J, Rao S. Implications of health sector reform for contraceptive logistics: a preliminary assessment for sub-Saharan Africa; 2000. Available from: http://www.popline.org/node/174270. [Last accessed on 12 May 2016].

11. USAID. Delivery team topping up: Bringing about reliable distribution in difficult environments; 2008. Available from: http://deliver.jsi.com/dlvr_content/resources/allpubs/logistic sbriefs/ZW_DTTUBrin.pdf. [Last accessed on 27 Jun 2016].

12. Lijdsman C, Onyango C, Gatera A, Saleeb S, Tarrafeta B, Gabra M. Assessment of the health commodity supply sector in Rwanda. USA. Arlington VA. Rational pharmaceutical management, plus program, for USAID; 2003. Available from: http://pdf.usaid.gov/pdf_docs/Pnadk130.pdf. [Last accessed on 27 Jun 2016].

13. Mathew BI, Gadde RA, Nutakki PR, Doddayya HI. Assessment of drug dispensing practices using WHO patient care and health facility indicators in a private tertiary care teaching hospital. Int J Pharm Sci 2013;5:368-71.

14. Singh PV, Tatambhotla A, Kalvakuntla R, Chokshi M. Understanding public drug procurement in India: a comparative qualitative study of five Indian states. Br Med J 2013;3:e001987.

15. Kangwana BP, Kedenge SV, Noor AM, Alegana VA, Nyandigisi AJ, Pandit J, et al. The impact of retail sector delivery of artemetherlumefantrine for malaria, treatment of children under five in Kenya: a cluster randomized controlled trial. Available from: http://journals.plos.org/plosmedicine/article?id=10.1371/ journal. pmed.1000437. [Last accessed on 14 Jul 2016].

16. Iqbal MJ, Geer MI, Dar PA. Availability and stock outs of essential pediatric medicines across different levels of care in one district. Indian J Pharm Practice 2015;8:17-76.

\section{How to cite this article}

- Mir Javid Iqbal, Mohammad Ishaq Geer, Parvez Ahamd Dar. Development of an indicator-based tool for the assessment of medicines selection practices in various public sector hospitals. Int J Pharm Pharm Sci 2016;8(11):205-208. 